\title{
Simple and efficient micro-SPE tip-based sample preparation workflow to enable sensitive proteomic profiling of limited samples (200 to 10,000 cells)
}

James C. Kostas ${ }^{1}$, Michal Greguš ${ }^{1}$, Jan Schejbal ${ }^{1}$, Somak Ray ${ }^{1} \&$ Alexander $R$. Ivanov $^{1 *}$

${ }^{1}$ Barnett Institute of Chemical and Biological Analysis, Department of Chemistry and Chemical Biology, Northeastern University, 360 Huntington Ave., Boston, Massachusetts 02115, United States

\section{Supporting Information}

Keywords: sample preparation, on-membrane digestion, micro-SPE tip, limited samples, label-free quantitation, bottom-up nanoLC-MS-based proteomics, OMSET (On-Micro Solid-phase Extraction Tip)

*Corresponding author: Prof. Alexander R. Ivanov, a.ivanov@northeastern.edu 


\section{Table of Contents}

\section{Supplementary methods}

Figure S1. Diagram of micro-SPE tip setup during digestion.

Figure S2. Ion density maps of starting material, eluate, and flow thru from HeLa protein digest loaded on micro-SPE tips.

Figure S3. Results of GO-term enrichment analysis conducted using proteomic profiling data. Recovery of proteins pertinent to specific cellular components was compared for starting material, eluate, and flow-through from HeLa protein digest loaded on micro-SPE tips.

Figure S4. Venn diagrams showing overlap of protein IDs from starting material and eluates from HeLa protein digest loaded on micro-SPE tips.

Figure S5. Venn diagrams showing overlap of proteins identified between representative technical and sample processing duplicates from HeLa protein digest loaded on micro-SPE tips. Figure S6. Results of GO-term enrichment analysis conducted using proteomic profiling data. Recovery of proteins pertinent to specific cellular components was compared for digestion sequences.

Figure S7. Numbers of protein group and peptide group identifications for different micro-SPE tip packing styles.

Figure S8. Representative base ion chromatographs for U937 cells processed using OmSET.

Figure S9. Representative ion density maps for U937 cells processed using OmSET.

Figure S10. Results of GO-term enrichment analysis conducted using proteomic profiling data. Recovery of proteins pertinent to specific cellular components was compared for OmSET and in-solution digestion.

Figure S11. Distribution of proteins identified using OmSET and in-solution digestion according to physiochemical properties.

Figure S12. Distribution of proteins quantified using OmSET and in-solution digestion according to LFQ protein abundance.

Figure S13. Boxplots showing distributions of pairwise correlations for runs of U937 cells processed using OmSET.

Table S1. Numbers of protein and peptide group identifications from U937 cells processed using OMSET.

Table S2. Published results from alternative sample processing platforms.

Table S3. Comparison of LC-MS/MS conditions between OmSET and MICRO-FASP sample preparation platforms.

References

SupportingInformation.xlsx 


\section{Comparison of micro-SPE tip packing styles}

Micro-SPE tips were packed as described with two adjustments made for four total packing styles. In Style 1, two cores of the membrane were punched one after the other with the blunt tip needle before both were simultaneously transferred into the tip packing with firm pressure until strong resistance was met. In Style 2, the membrane cores were taken in the same way as in Style 1, but, this time, the packing was done more gently until any resistance was felt. In Style 3, one core of the membrane was punched with the blunt tip needle before packing into the tip with firm pressure. This was repeated once more for two total cores. In Style 4, the cores were transferred one at a time as in Style 3, but the packing was done with gentle pressure. 4,000 U937 cells were processed in duplicate for each tip packing style as described below. Each style was spun separately as flow rates vary based on the packing method. As a general rule, more firmly packed tips require longer spin times. For LC-MS analysis, a $1 / 10^{\text {th }}$ aliquot was injected two times for duplicate LC-MS runs on a Q-Exactive HF-X mass spectrometer.

\section{Spectral library construction}

The Skyline (v20.1.0.76) software ${ }^{1}$, with built-in BiblioSpec spectral library building tool, was used to import DDA search results, construct the library and visually inspect it. The DDA search results comprised of three Proteome Discoverer (PD) msf format MS/MS search result files corresponding to three technical replicates of $\sim 10,000$ U937 cell samples run with a 60 min LC gradient and searched against a Human sequence database using SequestHT. The $m s f$ files were imported to Skyline using Skyline's "Import DDA peptide search" menu. The Skyline peptide confidence cut-off score was set to 0.99, "Precursor mass analyzer" parameter was set to "Centroided" as recommended by Skyline for Thermo RAW files and mass accuracy was set to $10 \mathrm{ppm}$. For retention time filtering, scans only within 2 minutes of MS/MS IDs were used. The other parameters chosen were matched to the original DDA search wherever possible. Skyline internally invoked the Bibliospec component "BlibBuild" to build a redundant library from the DDA data, which was subsequently filtered by the component "BlibFilter" to build a non-redundant library. The non-redundant library created by BlibFilter (*.blib) was used for further processing.

The non-redundant * blib file was then converted to *.MS2 format ${ }^{2}$, a prerequisite intermediate format for final conversion to *.sptxt. For the MS2 conversion, BiblioSpec was built from source (https://github.com/ProteoWizard/pwiz) using Microsoft Visual Studio 2017. The Blib2MS2 helper program from BiblioSpec suite was used to convert the blib format spectral library to MS2 format using the following command:

\section{BlibToMS2.exe -m 6 -i 3 -v all <speclib.NR.blib>}

The *.ms2 format library thus created was next converted to a *.sptxt format library using SpectraST ${ }^{3}$ command line tool bundled with the Trans Proteomic Pipeline software suite ${ }^{4}$. No decoy spectra were added during the SpectraSt conversion as decoys would be added later by PD. The *.sptxt format spectral library file was then imported to PD using its spectral library 
import tool. The *.sptxt format library was converted to a NIST MSP format file internally, decoys were added, and the library was used to search MS/MS spectra using the MSPepSearch software tool.

\section{Kernel density estimation plots}

Comparisons of physiochemical properties of proteins identified from OmSET sample preparation and in-solution digest of $U 937$ cells were produced as described previously ${ }^{5}$. Briefly, the R "Peptides" package (v3.6.1) was used to calculate GRAVY scores, as described previously 6 , and the Python "Seaborn" package was used to generate kernel density plot visualizations.

Comparisons of LFQ protein abundance distributions were carried out in a similar way. LFQ abundances were first normalized to fit a 0-1 range before plotting using the Python "Seaborn" package to generate kernel density plot visualizations. 


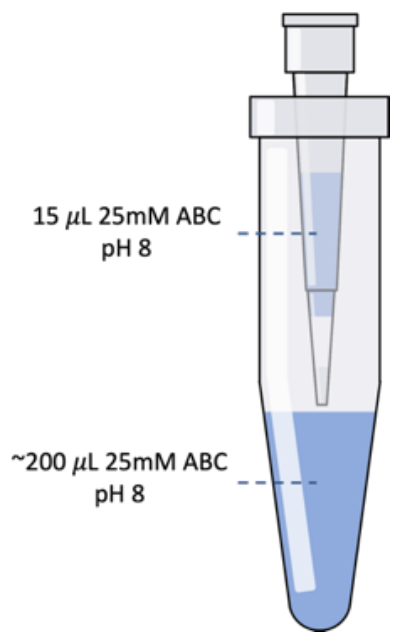

Figure S1. Diagram showing considerations we make to ensure that the column remains wetted during the overnight digestion step. 
A

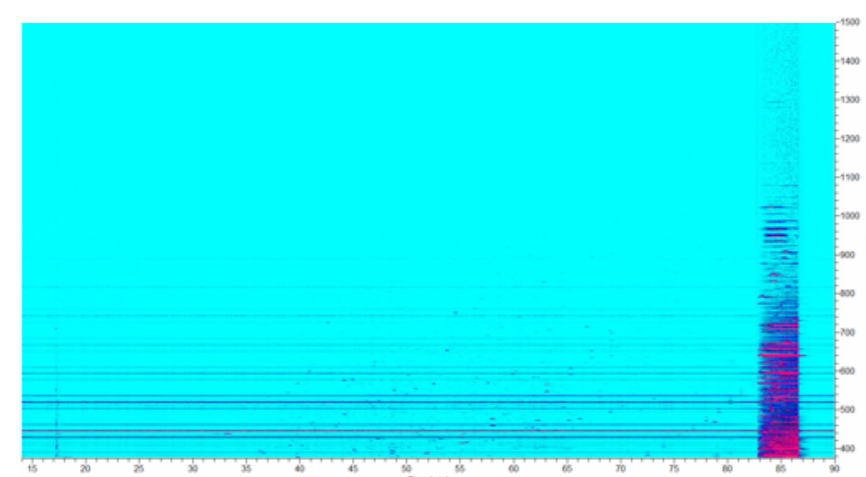

D

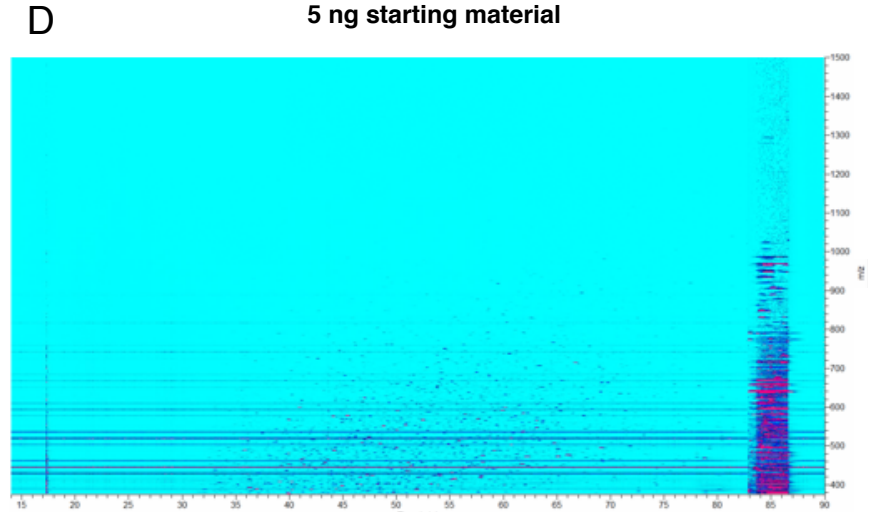

B

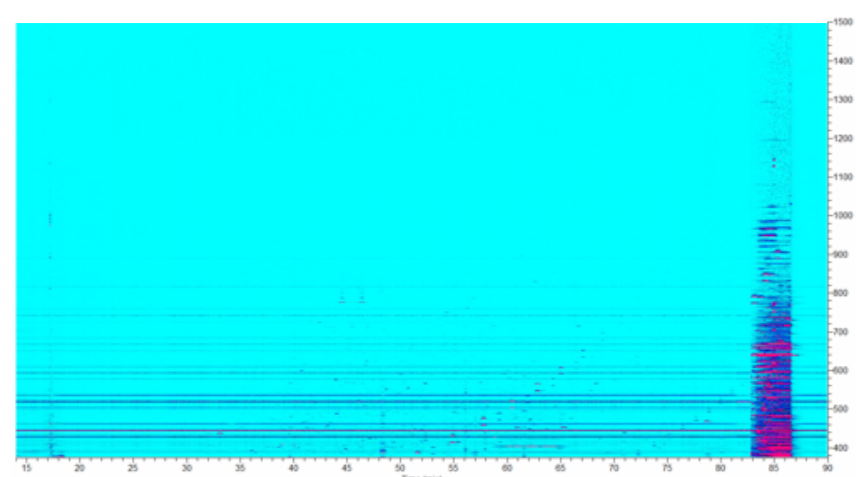

E

5 ng eluate

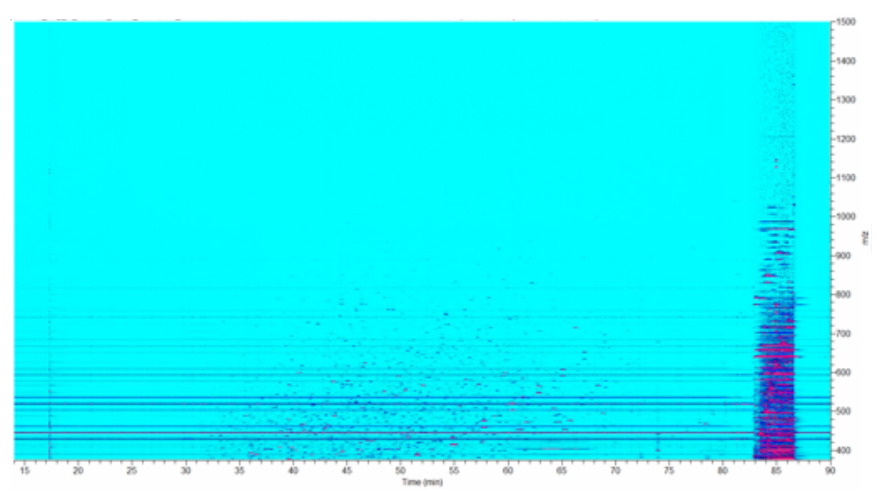

C

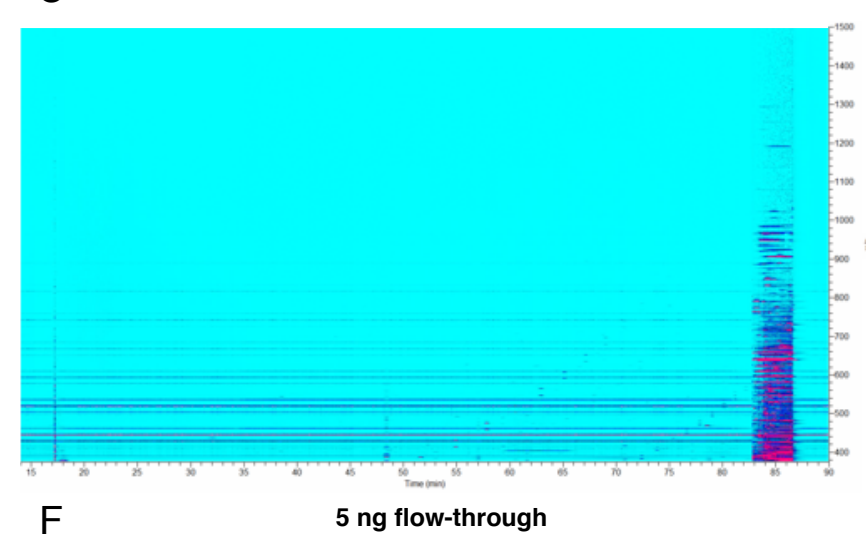


G

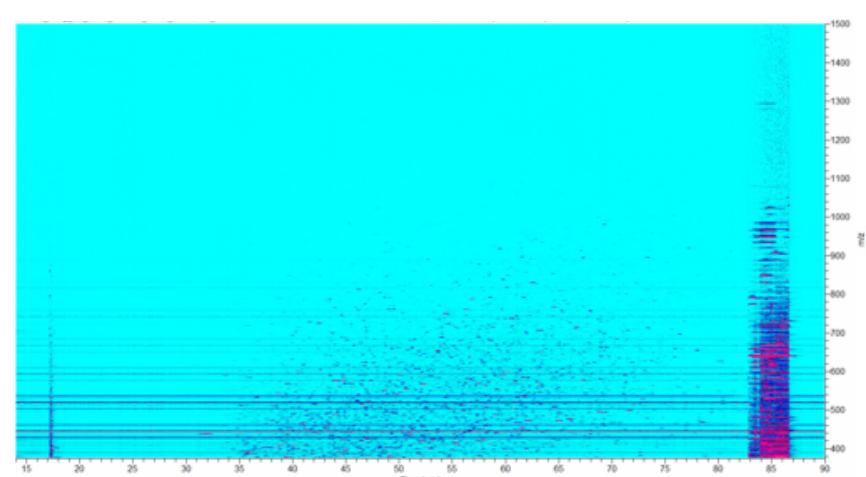

J

$50 \mathrm{ng}$ starting material

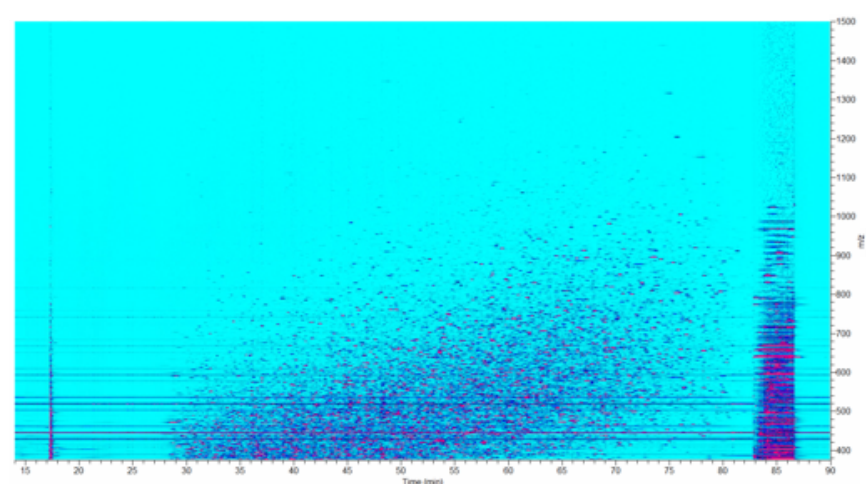

H

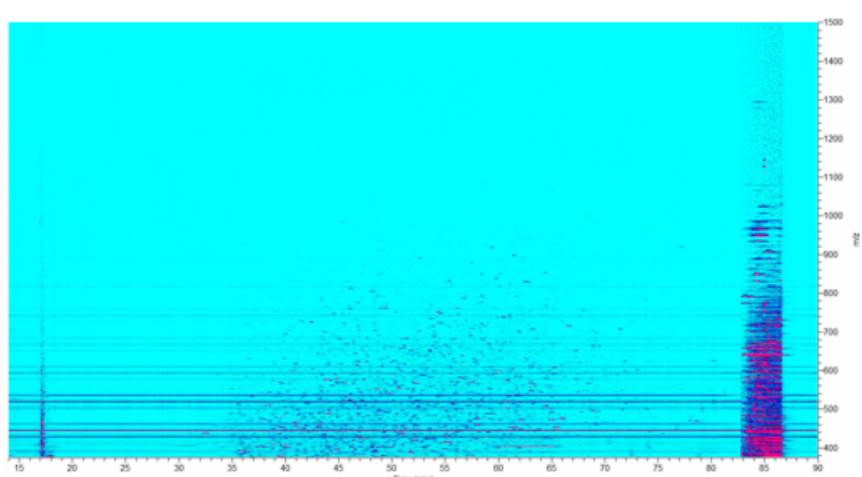

K

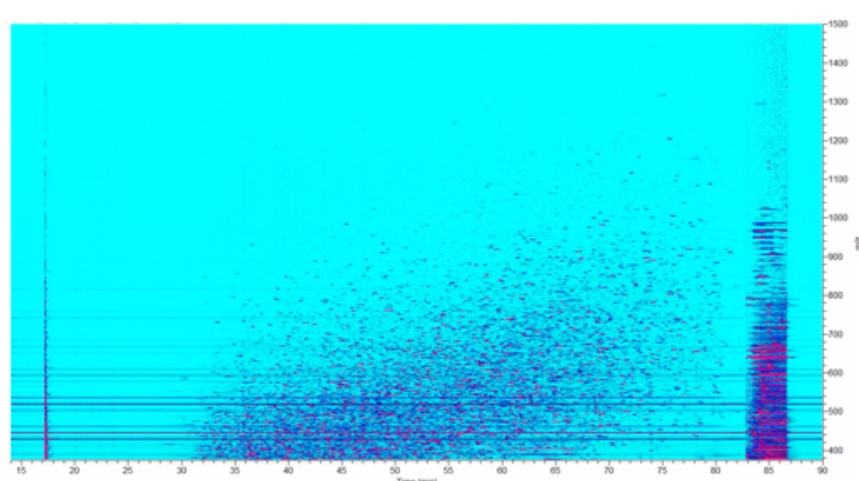

$10 \mathrm{ng}$ flow-through

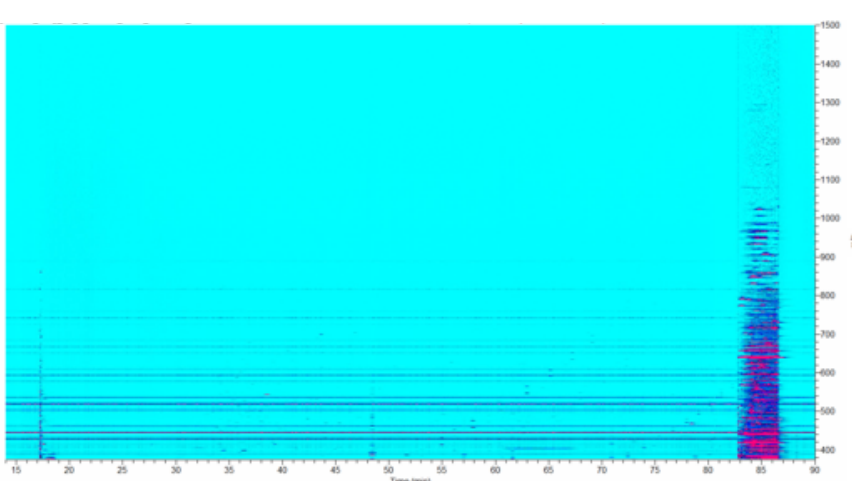

L

$50 \mathrm{ng}$ flow-through

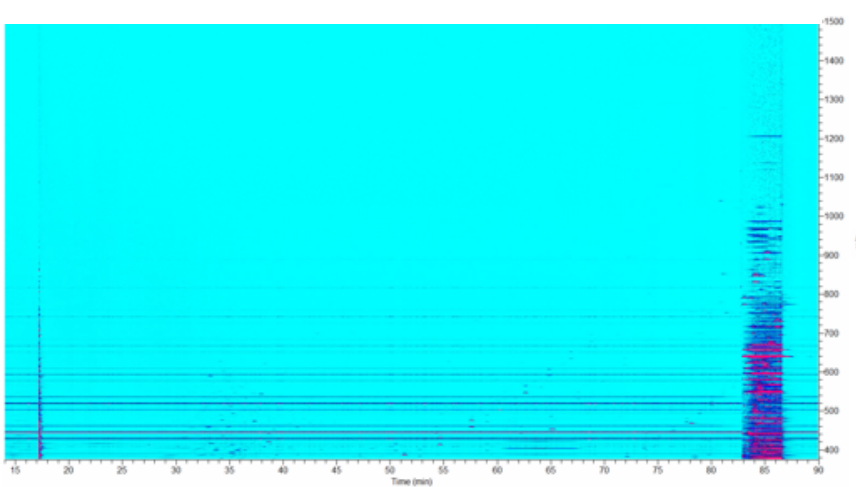




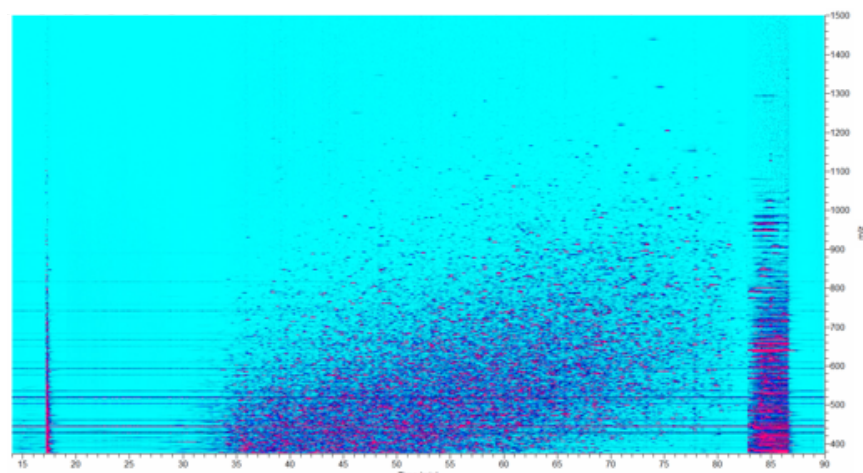

$\mathrm{P}$

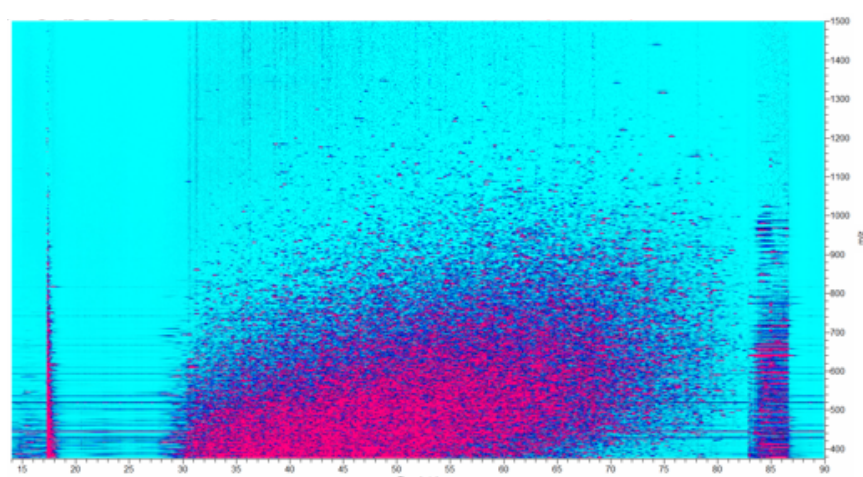

$\mathrm{N}$

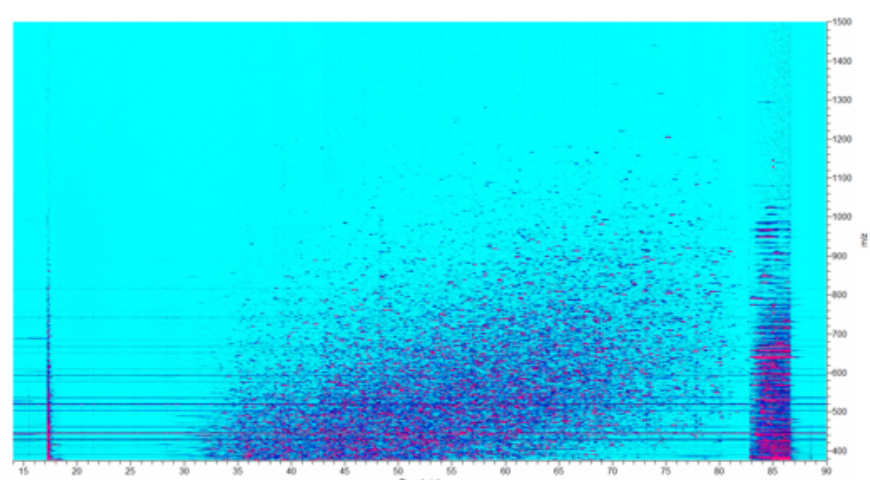

500 ng eluate

\section{Q}

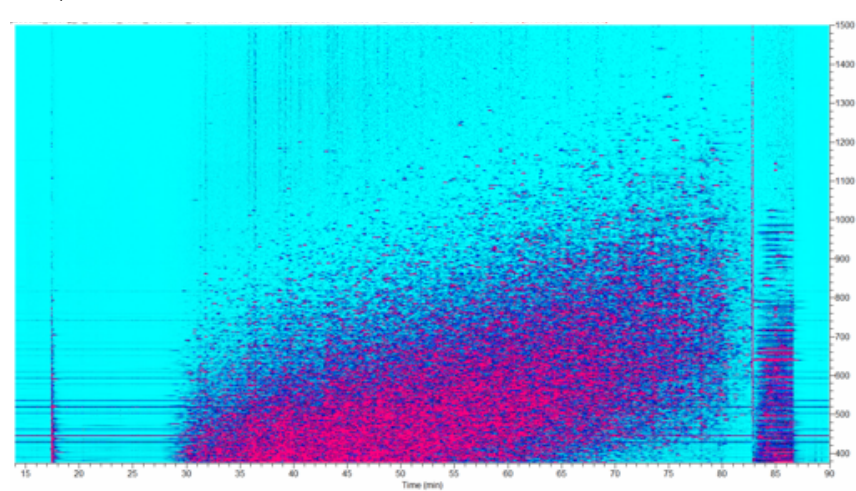

O

$100 \mathrm{ng}$ flow-through

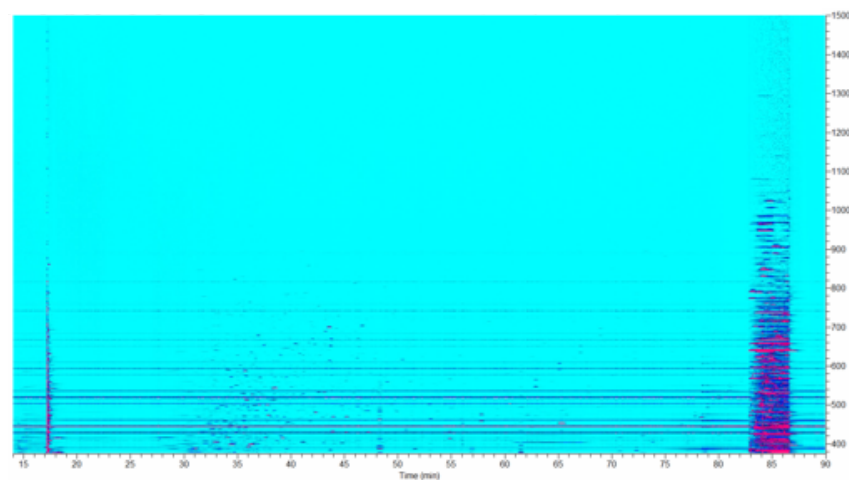

$\mathrm{R}$

$500 \mathrm{ng}$ flow-through

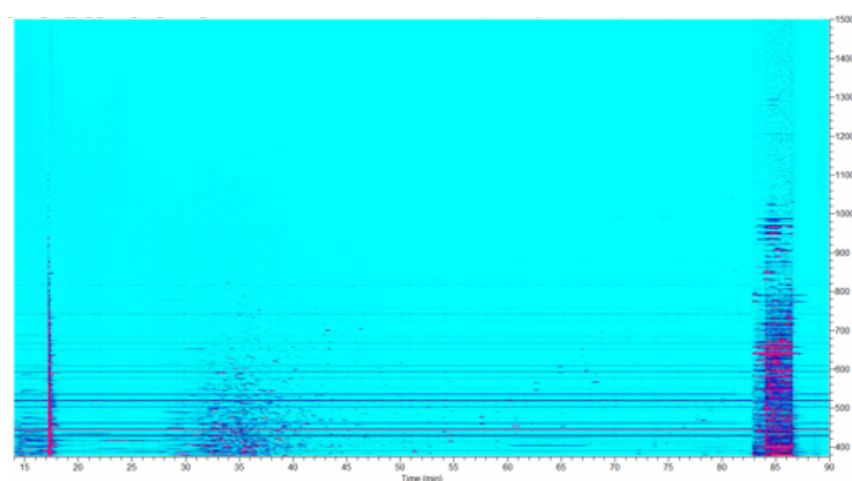

Figure S2. Representative ion density maps for the starting material, eluate, and flow-through fraction from 1 (A, B, C), 5 (D, E, F), 10 $(\mathbf{G}, \mathbf{H}, \mathbf{I}), 50(\mathbf{J}, \mathbf{K}, \mathbf{L}), 100(\mathbf{M}, \mathbf{N}, \mathbf{O})$, and $500 \mathrm{ng}(\mathbf{P}, \mathbf{Q}, \mathbf{R})$ of HeLa digest standard loaded onto micro-SPE tips. 1/10 th $^{\text {th }}$ the sample injected for LC-MS analysis. For example, from the $100 \mathrm{ng}$ starting material condition, an aliquot corresponding to $10 \mathrm{ng}$ was analyzed. The same normalization was applied to all panels. NL $=1.5 \mathrm{E} 6$. 


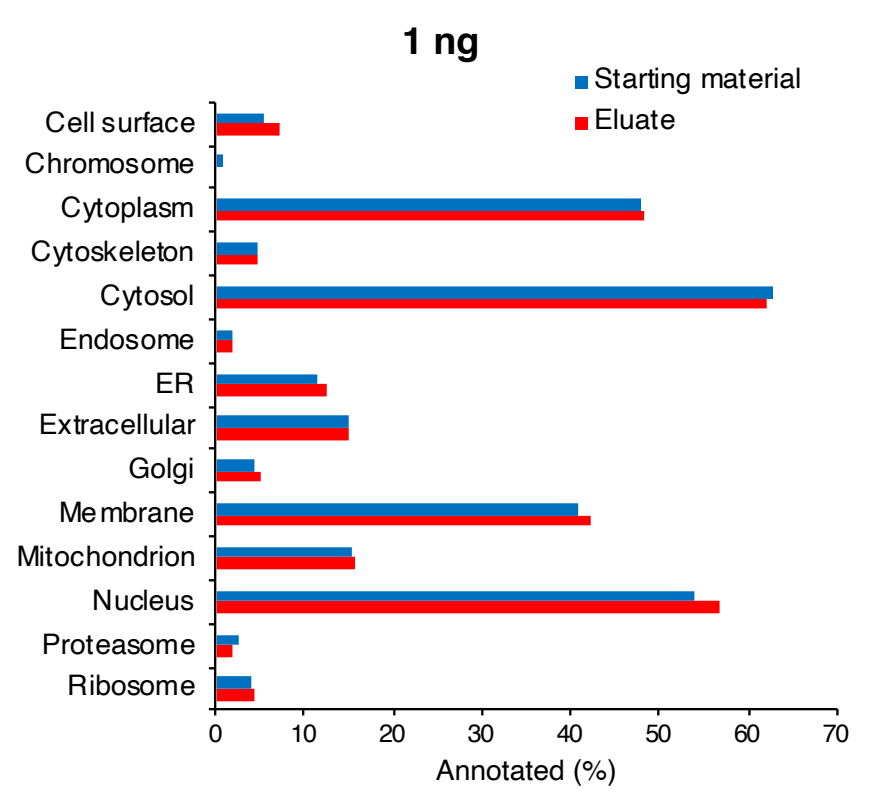

$50 \mathrm{ng}$

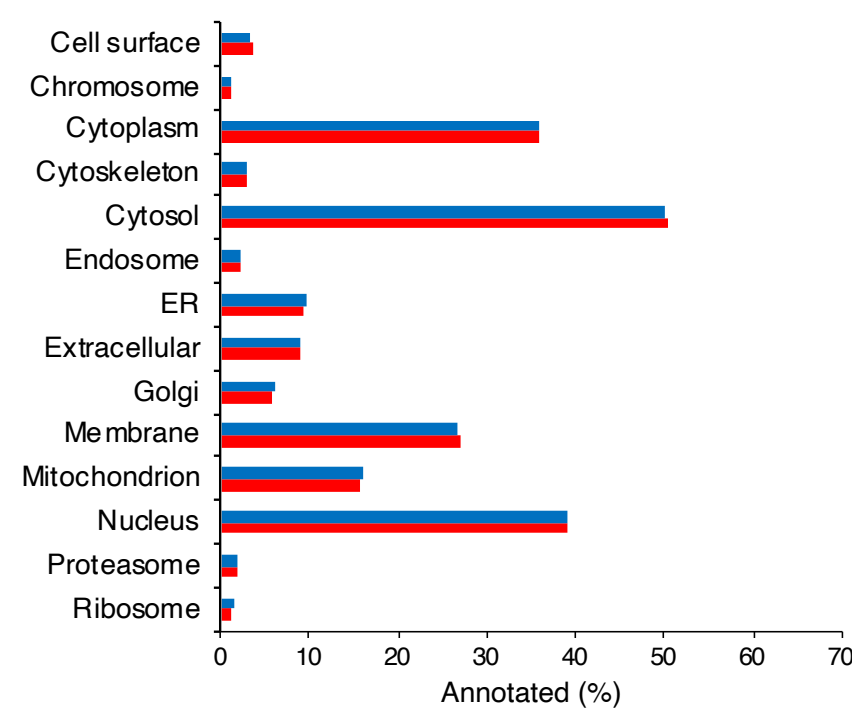

$5 \mathrm{ng}$

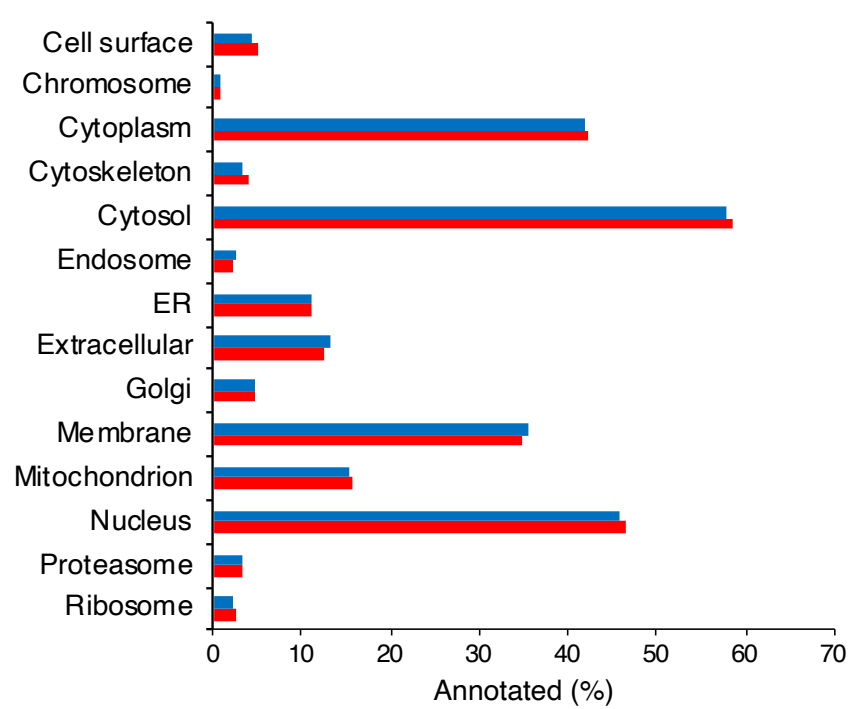

$100 \mathrm{ng}$

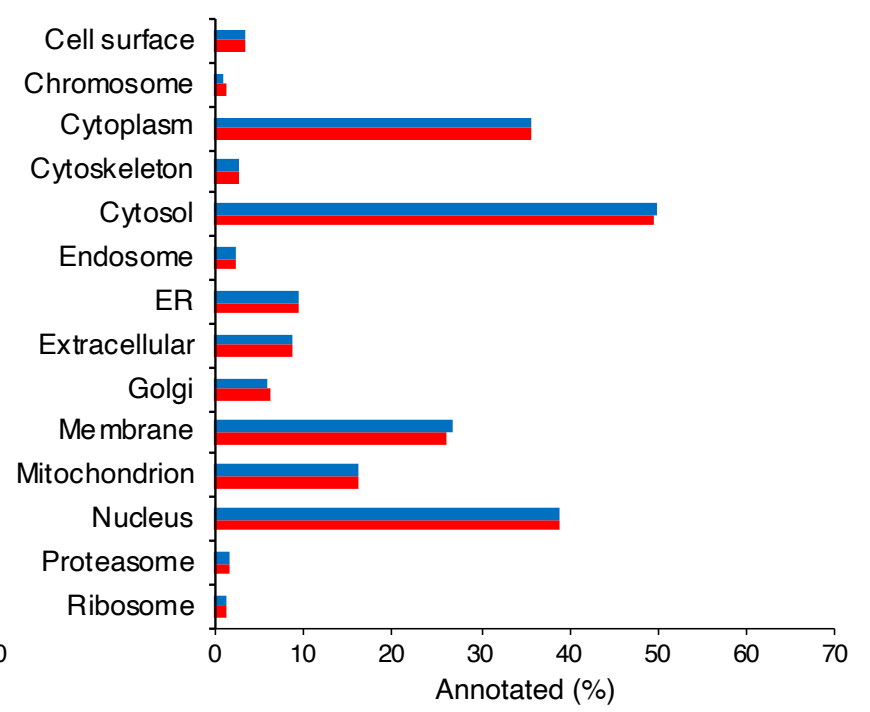

$10 \mathrm{ng}$

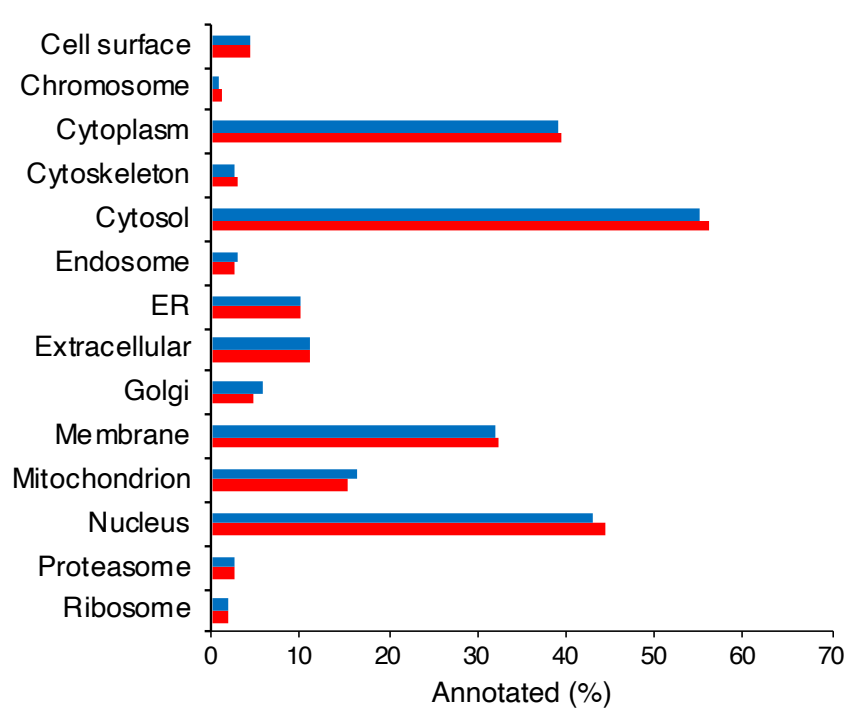

$500 \mathrm{ng}$

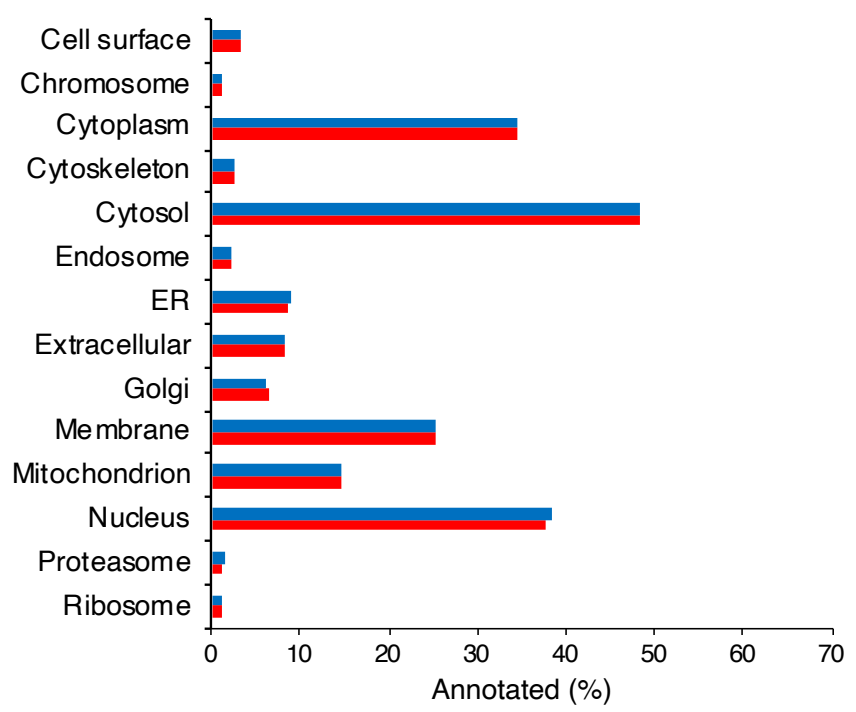


Figure S3. Results of GO-term enrichment analysis conducted using proteomic profiling data. Recovery of proteins pertinent to specific cellular components was compared for proteins identified in starting material and eluate for 1 (A), 5 (B), 10 (C), 50 (D), 100 (E), and 500 ng (F) of HeLa digest standard loaded on micro-SPE tips. 
A

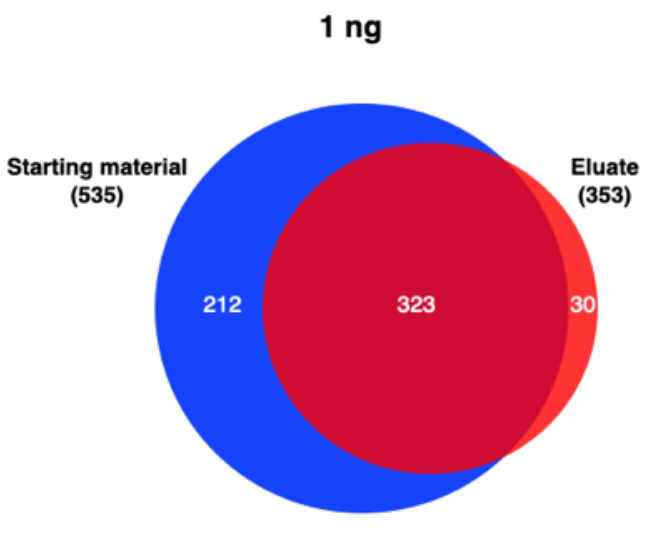

D

$50 \mathrm{ng}$

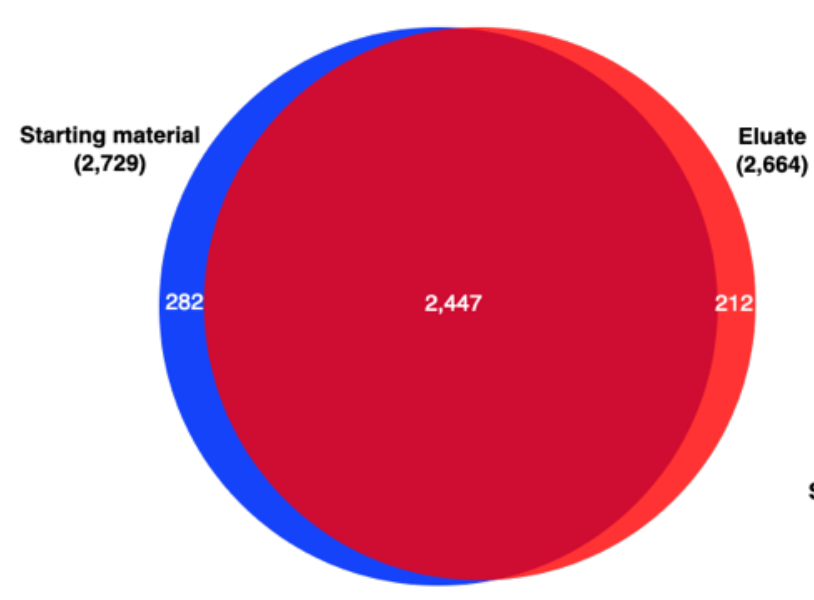

B

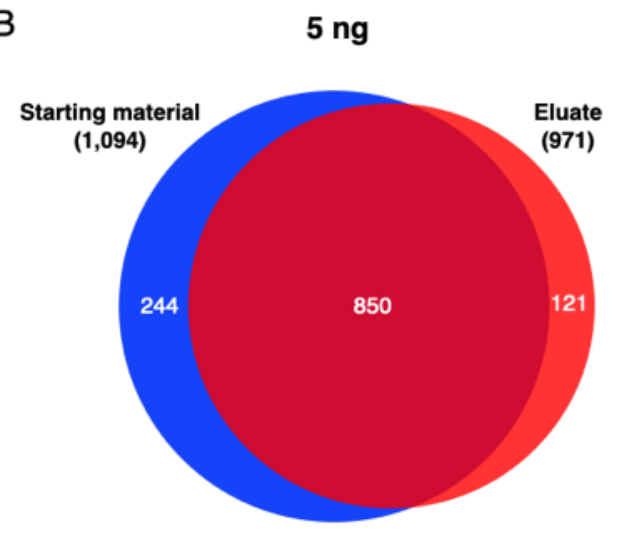

E

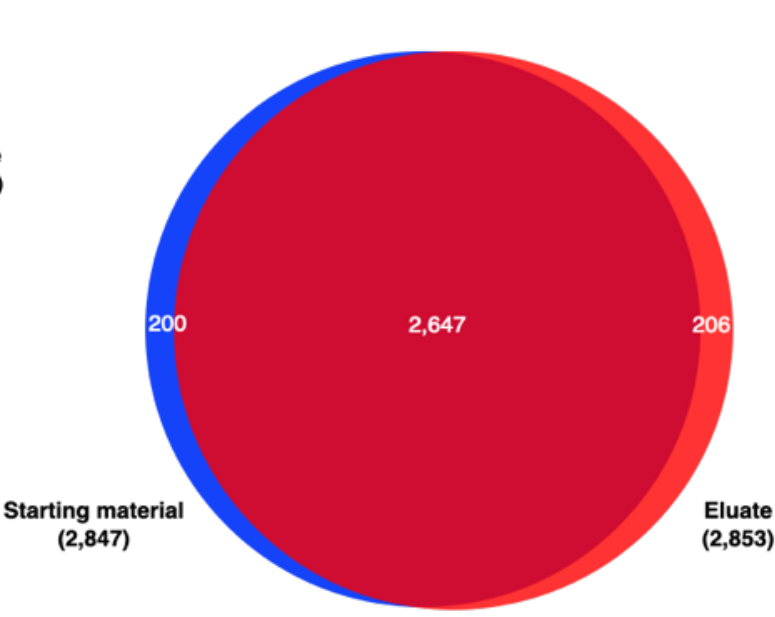

C

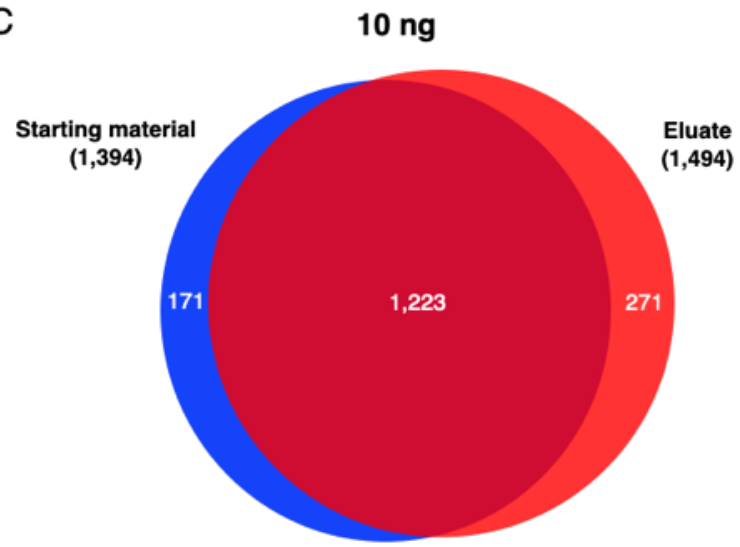

F

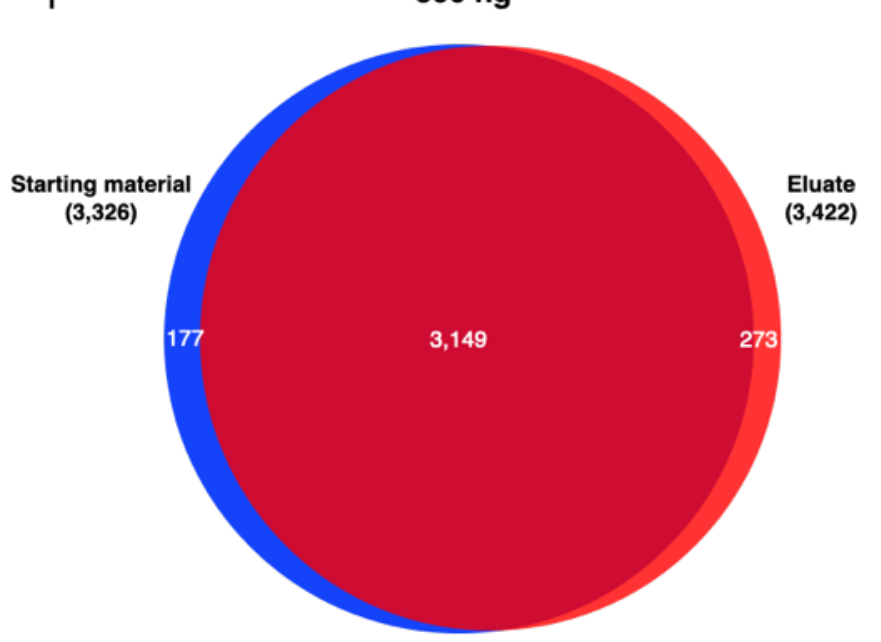

Figure S4. Venn diagrams showing the overlap of proteins identified in the starting material and eluate for 1 (A), 5 (B), 10 (C), 50 (D), $100(\mathbf{E})$, and $500 \mathrm{ng}(\mathbf{F})$ of HeLa digest standard loading on micro-SPE tips. 
A

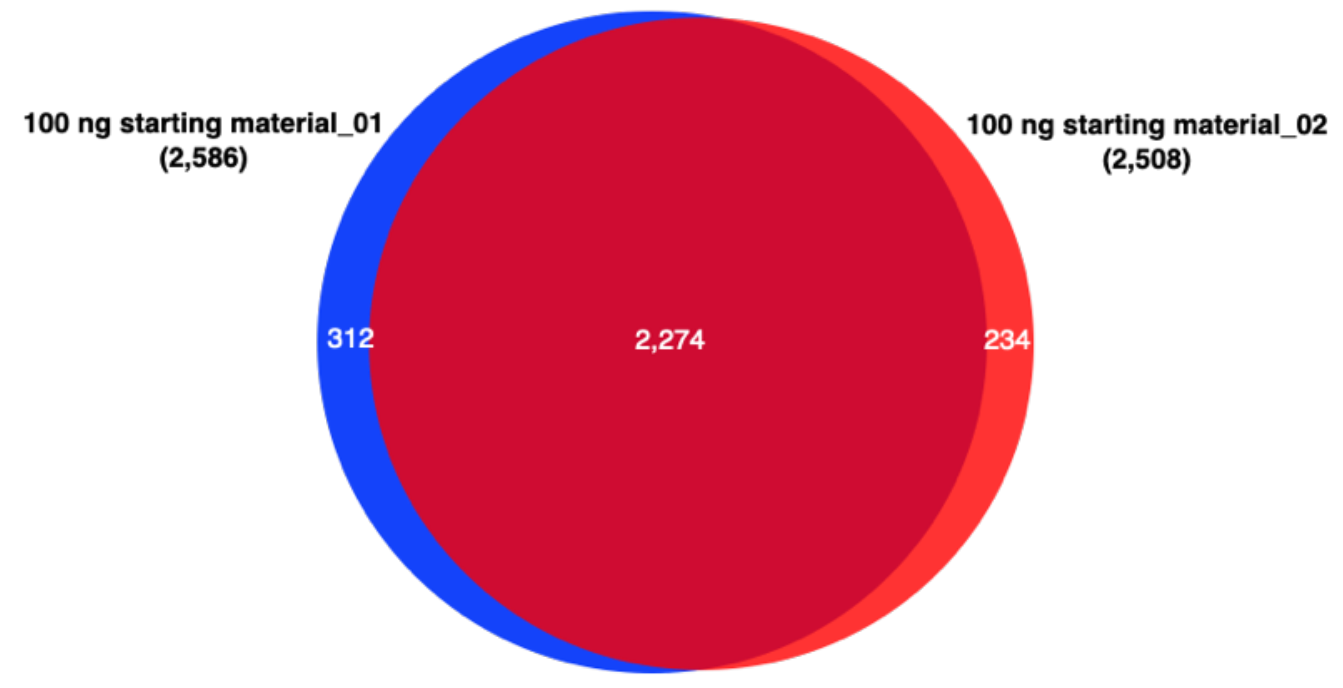

B

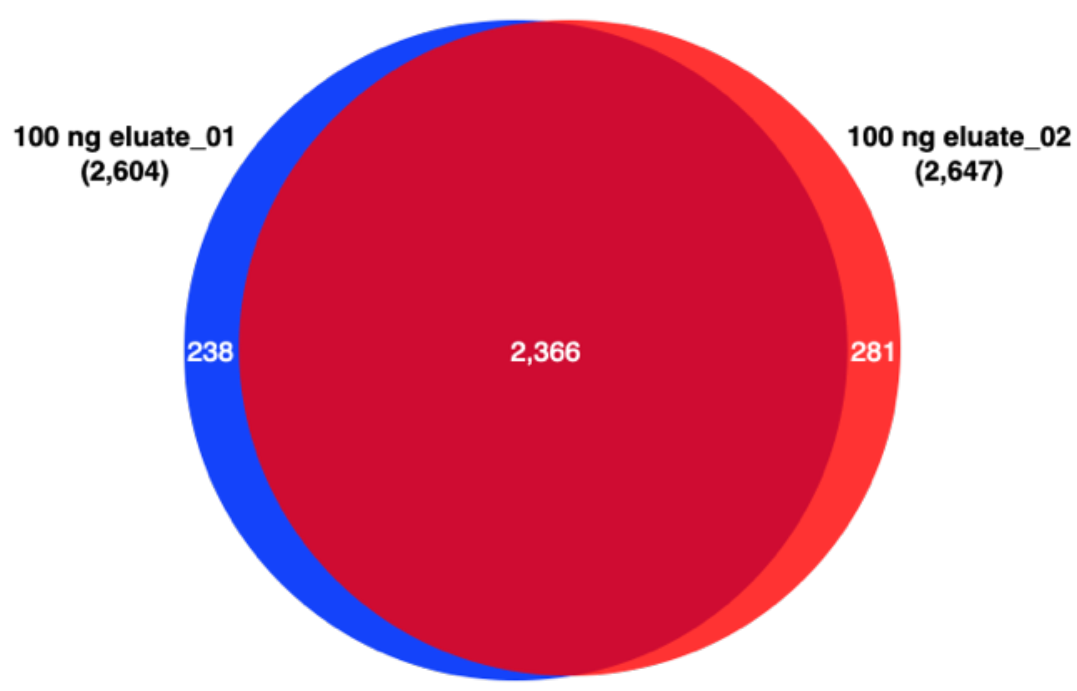

Figure S5. Venn diagrams showing the overlap of proteins identified in the selected representative LC-MS replicates for the starting material (A) and eluate (B) from $100 \mathrm{ng}$ (as a representative example) loaded on micro-SPE tips. 


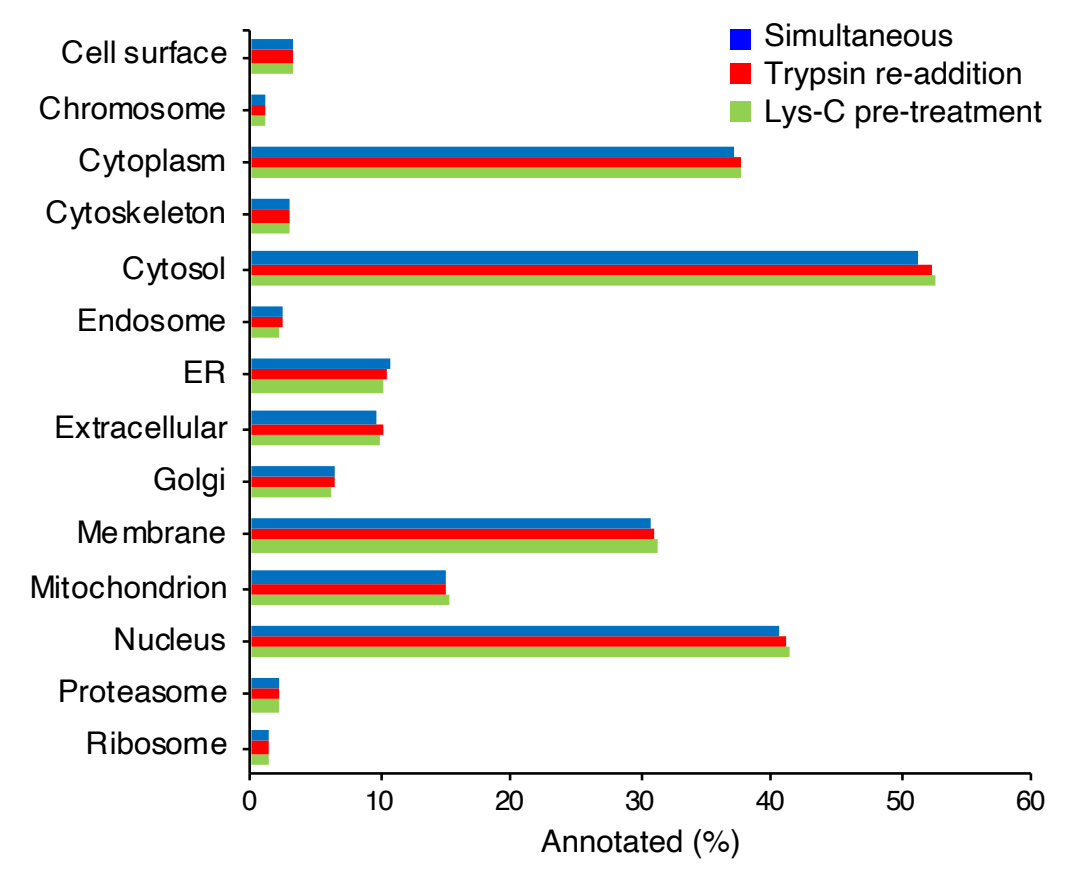

Figure S6. Results of GO-term enrichment analysis conducted using proteomic profiling data. Recovery of proteins pertinent to specific cellular components was compared for digestion sequences simult (blue), trypsin re-add (blue) and Lys-C pre-add (green).

A

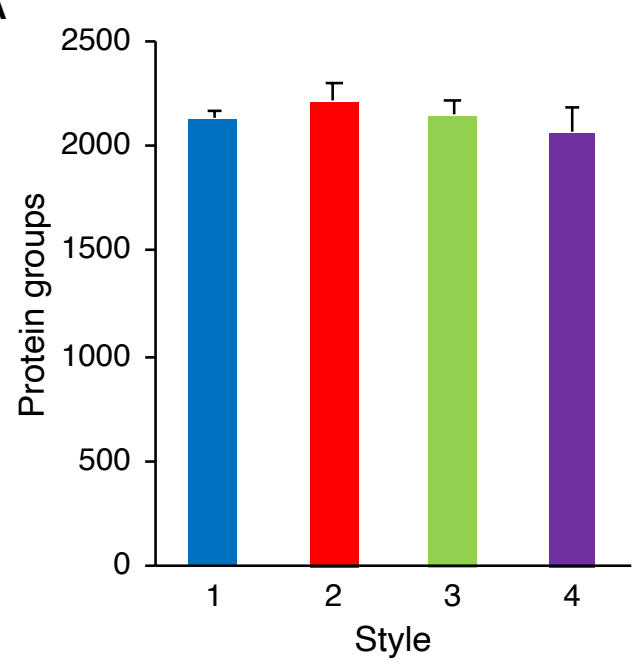

B

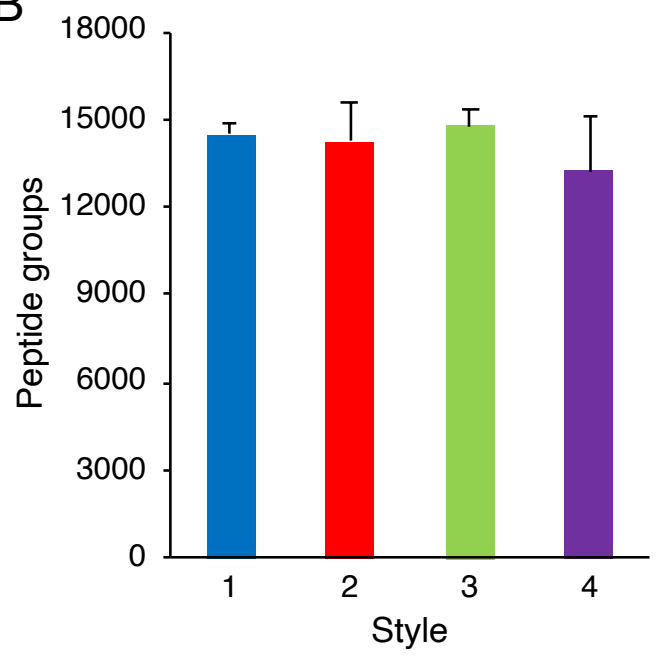

Figure S7. Numbers of protein groups (A) and peptide groups (B) identified using four different packing methods: two core transfer with firm packing ('Style 1'); two core transfer with gentle packing ('Style 2'); two single core transfers with firm packing ('Style 3'); and two single core transfers with gentle packing ('Style 4'). Error bars show standard deviation from duplicate LCMS runs of sample processing triplicates. 

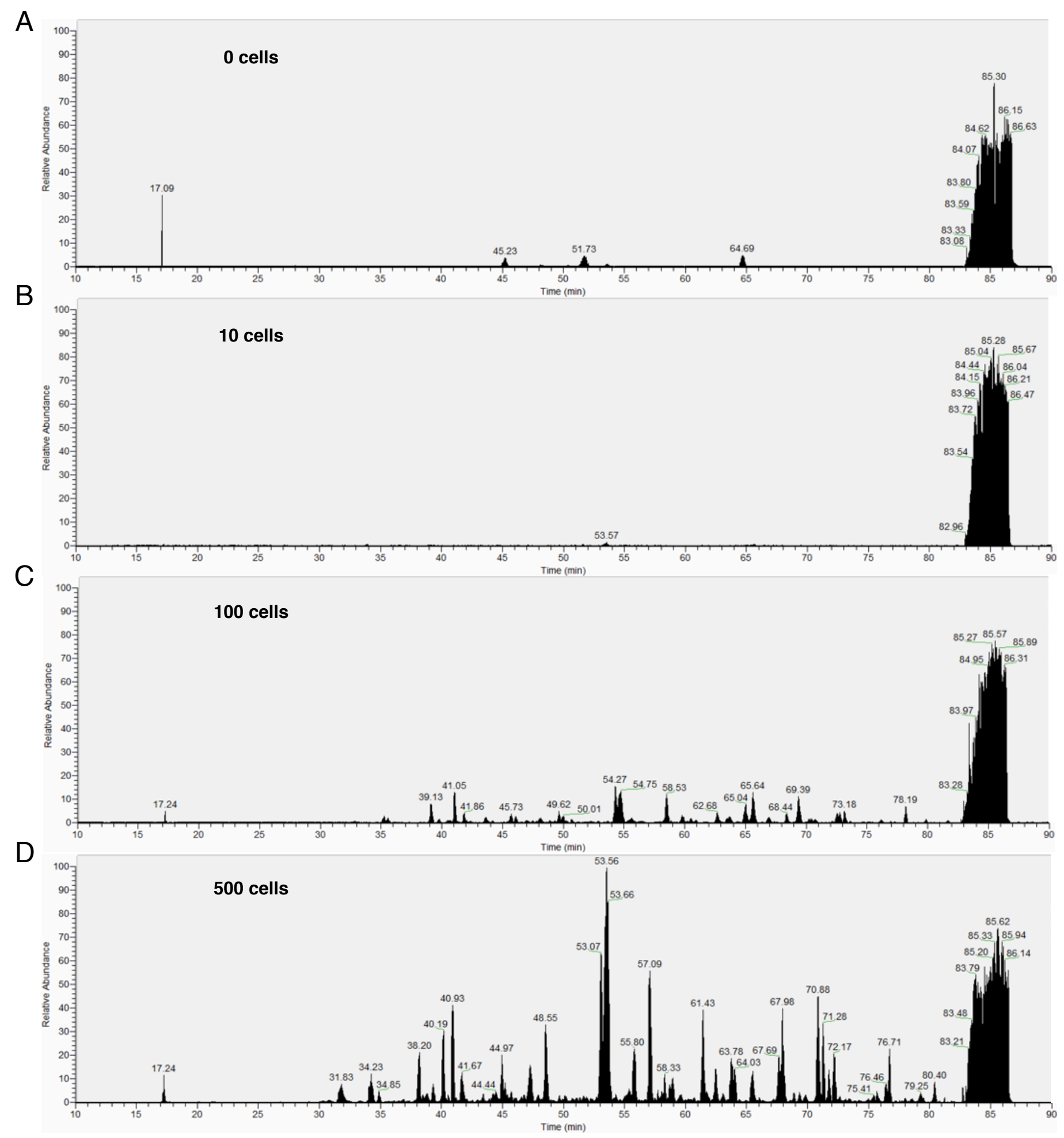

Figure S8. Representative base ion chromatographs for 0 (A), 10 (B), 100 (C), and 500 cellequivalents (D) injected from 0, 200, 2000, and 10000 U937 cell samples, respectively, prepared using OmSET. The same normalized intensity was used in all panels. NL=1.4E9. 
A

C
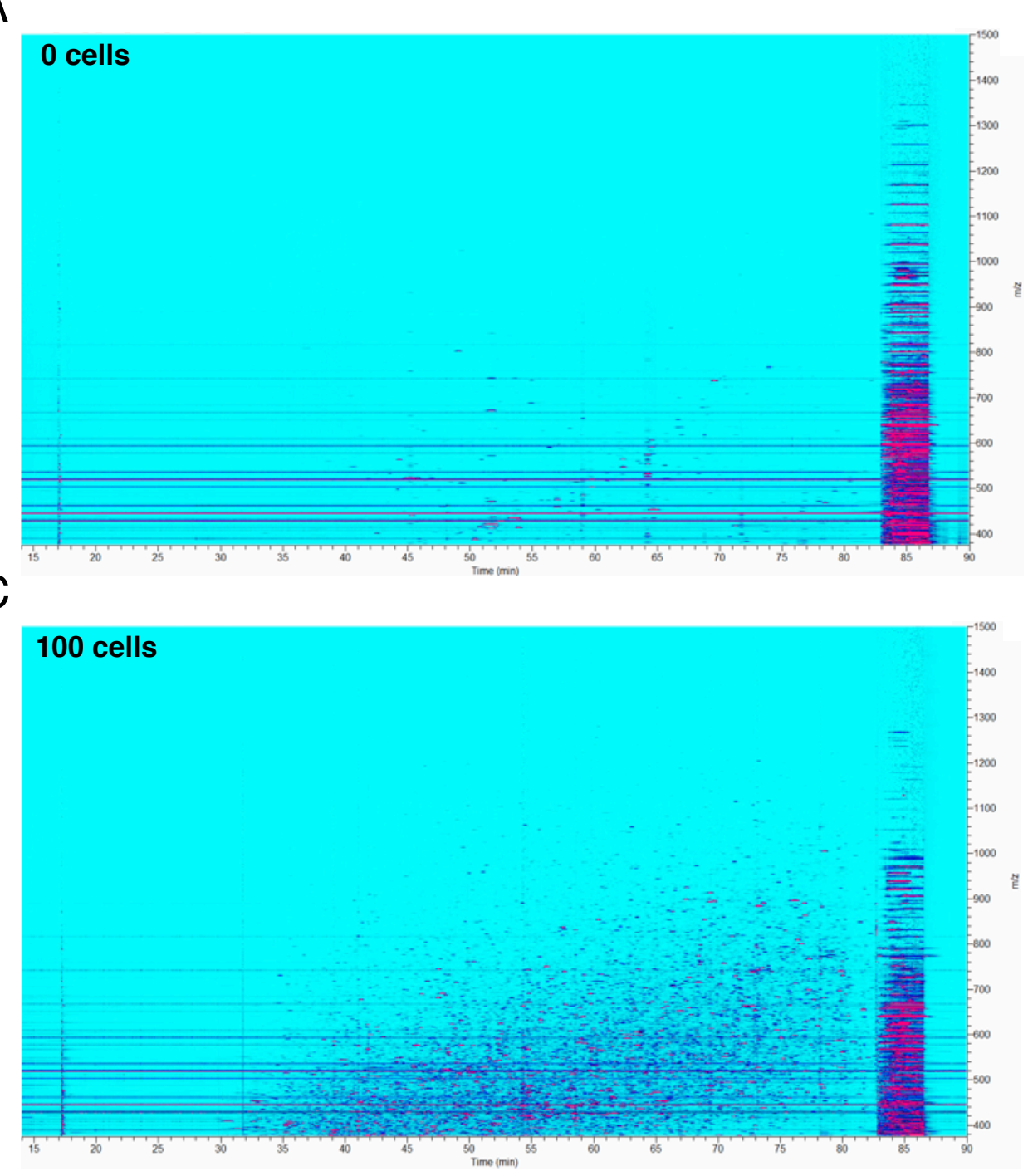

B
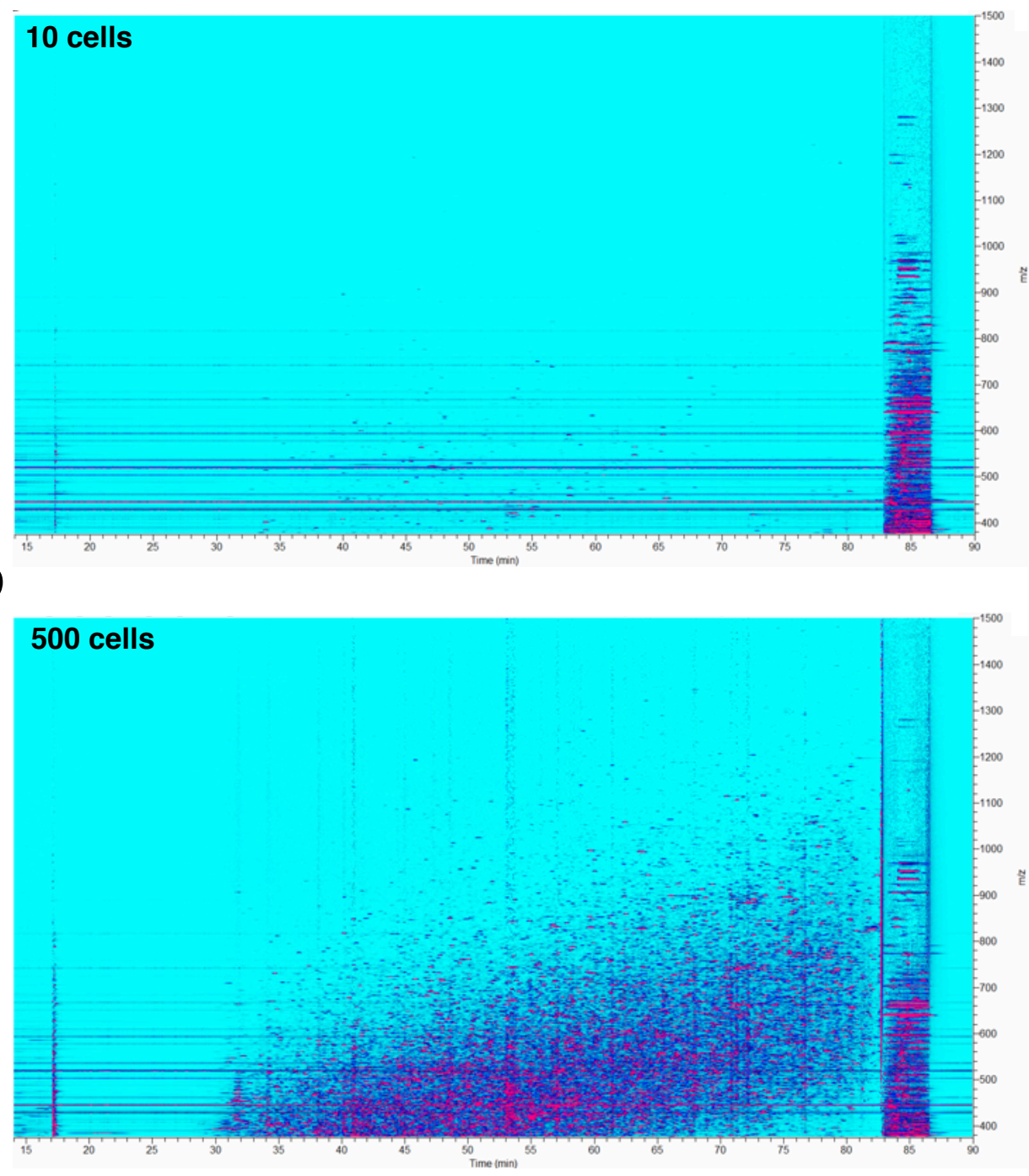

Figure S9. Representative ion density maps for 0 (A), 10 (B), 100 (C), and 500 cell-equivalents (D) injected from 0, 200, 2000, and 10000 U937 cell samples, respectively, prepared using OmSET. The same normalized intensity was used in all panels. NL=1.5E6. 


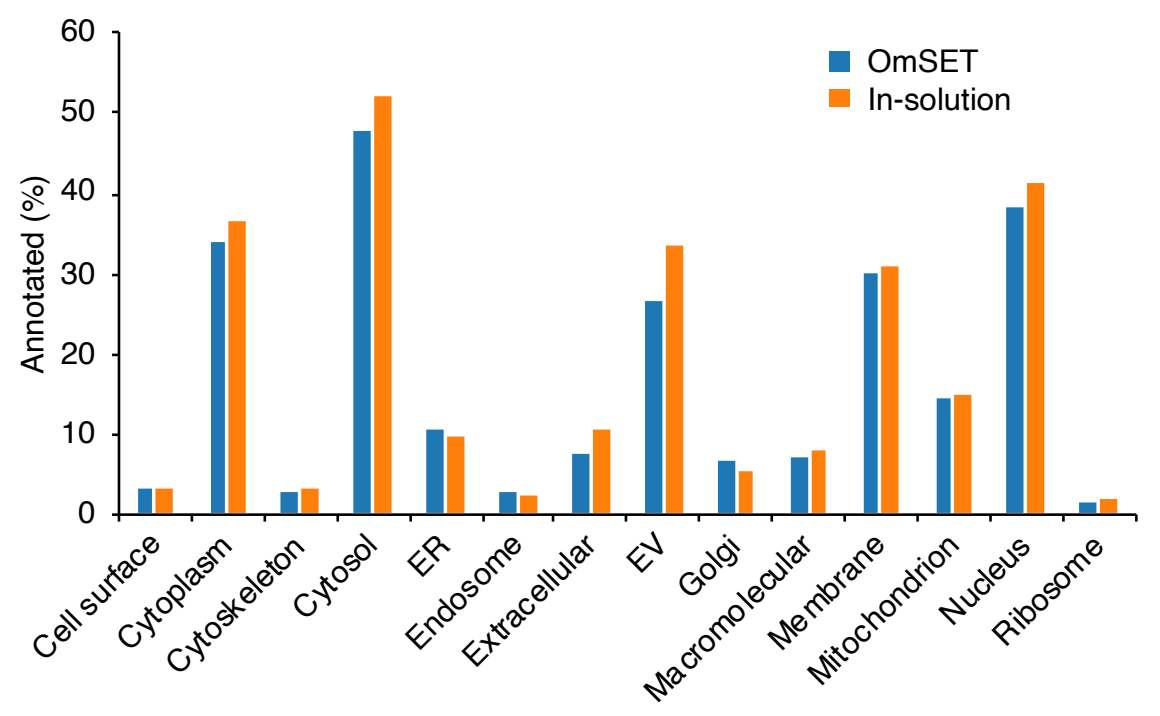

Figure S10. Results of GO-term enrichment analysis conducted using proteomic profiling data. Recovery of proteins identified using OMSET (blue) and in-solution digestion (orange) for U937 cells across all loading amounts are compared. 

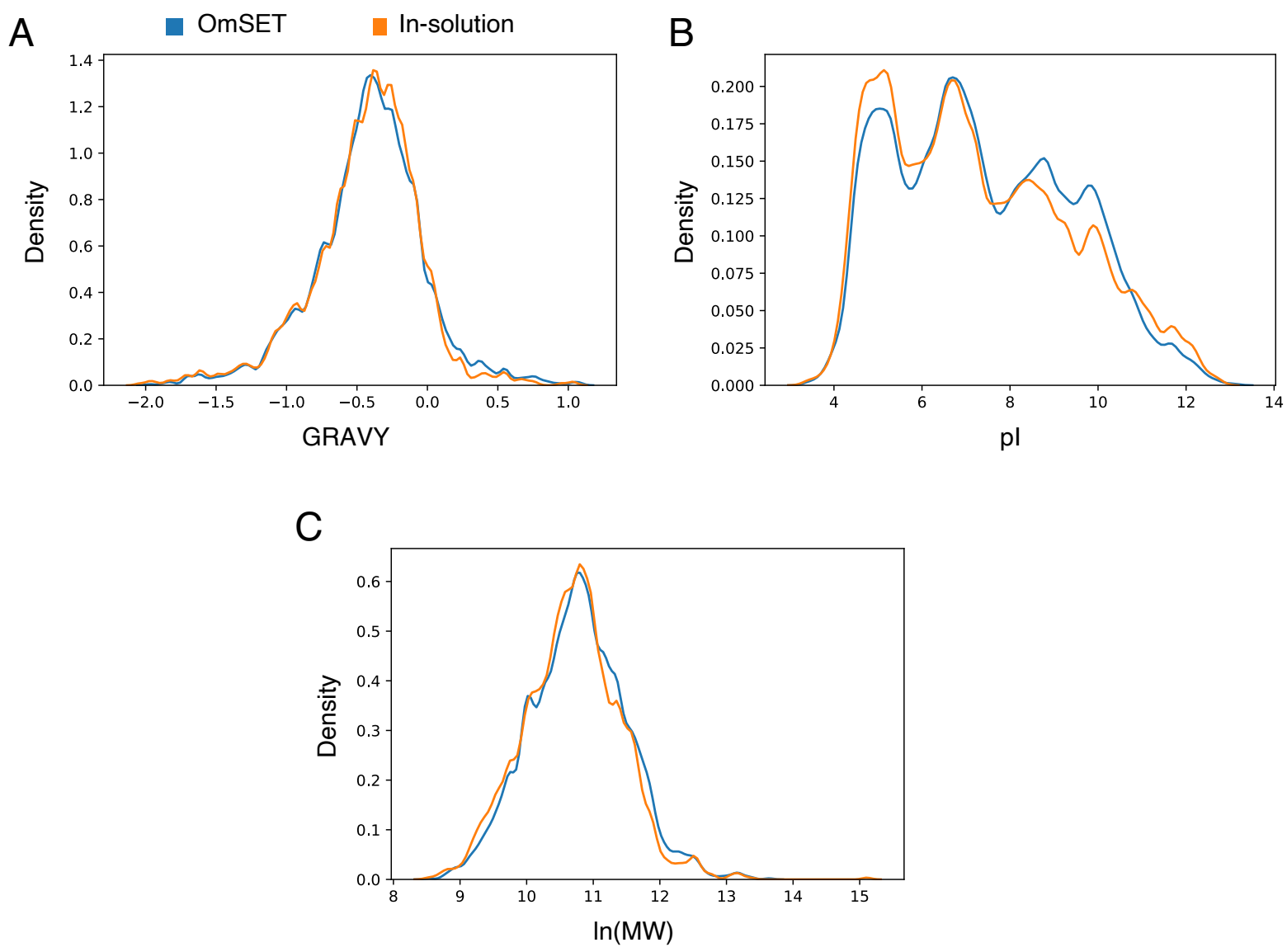

Figure S11. Distribution of proteins identified across all U937 cell loading amounts using OmSET sample preparation (blue) and in-solution digestion (orange) according to hydrophobicity (GRAVY) (A), isoelectric point (B), and molecular weight (C). 
A

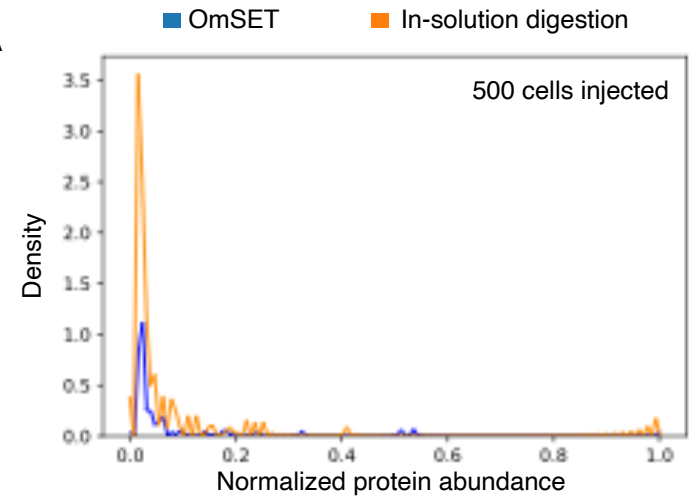

B

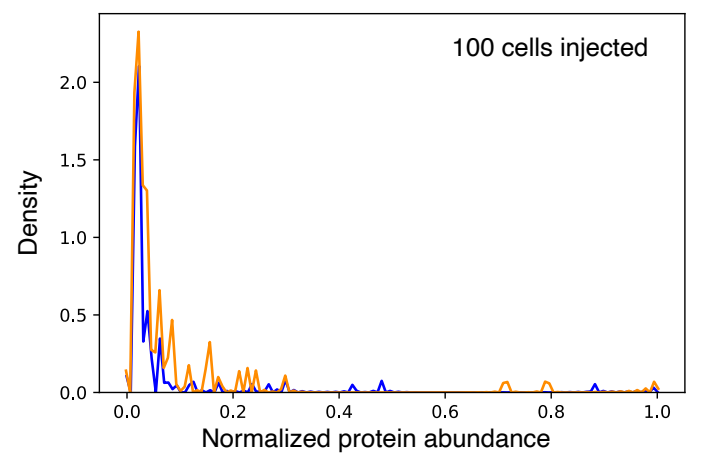

C

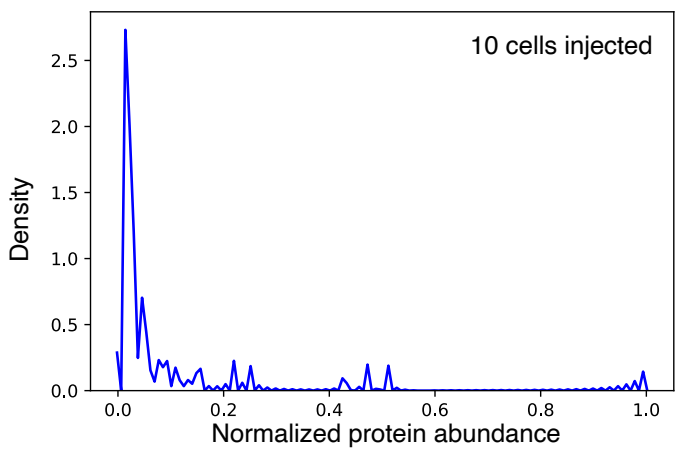

Figure S12. Distribution of protein LFQ abundances from proteins quantified using OmSET sample preparation (blue) as compared to in-solution digestion (orange). Results from 500-cell equivalent injections for OmSET $(N=2,480)$ and in-solution digestion $(N=1,469)(A), ~ 100$-cell equivalent injections from $\operatorname{OmSET}(N=2,465)$ and in-solution digestion $(N=1,128)(B)$, and $\sim 10$ cell equivalent injections from OmSET ( $N=953)(C)$ are shown. Protein LFQ abundances were normalized to fit a 0-1 scale. 


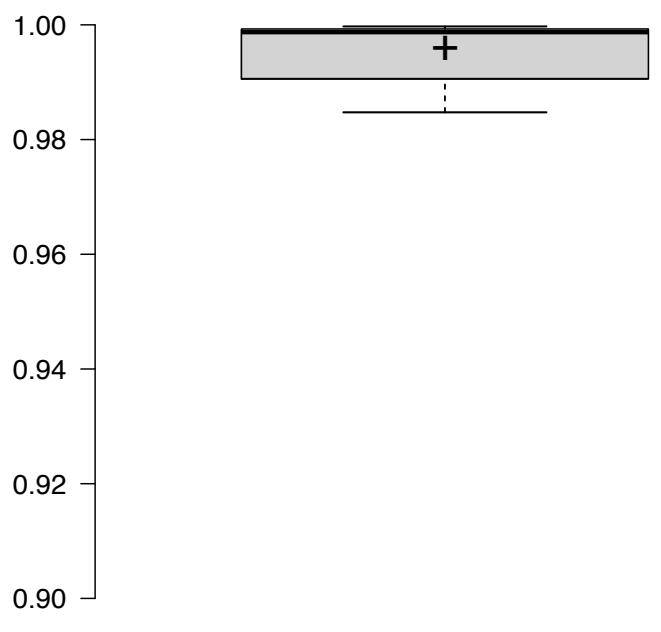

LC-MS technical replicates

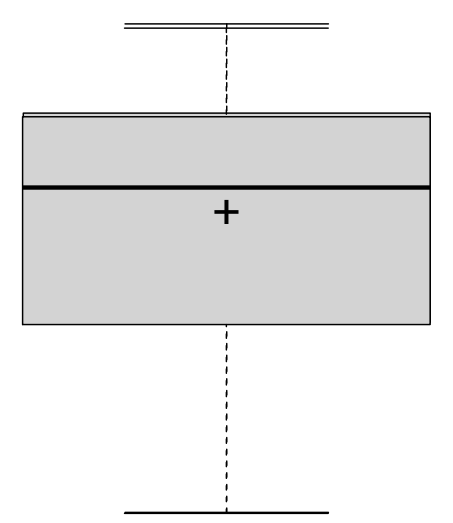

Sample processing replicates

Figure S13. Boxplots showing the distribution of $R^{2}$ values from pairwise correlations between LC-MS technical triplicates and between LC-MS runs from different sample processing duplicates. Whiskers extend to data points that are less than $1.5 \mathrm{X}$ the interquartile range from the 1 st/3rd quartile. Plus marks denote mean values. 
Table S1. Protein and peptide group identifications from 0, 10, 100, and 500 cell-equivalent injections from 0; 200; 2,000; and 10,000 human monocyte cells processed, respectively. Error bars show the standard deviation of triplicate LC-MS runs from sample processing duplicates ( $N=6$ in total). Identifications with the addition of spectral matching to the data processing workflow are also shown.

\begin{tabular}{c|cc|cc|} 
& \multicolumn{2}{c}{$\begin{array}{c}\text { Database searching only } \\
\text { cell equivalent injected }\end{array}$} & \multicolumn{2}{c}{$\begin{array}{c}\text { Database + spectral library } \\
\text { searching }\end{array}$} \\
\hline 0 & $23 \pm 6$ & $74 \pm 12$ & $39 \pm 10$ & $109 \pm 24$ \\
10 & $311 \pm 45$ & $727 \pm 147$ & $466 \pm 58$ & $1,266 \pm 208$ \\
100 & $1,828 \pm 105$ & $7,710 \pm 669$ & $1,923 \pm 88$ & $9,360 \pm 542$ \\
500 & $2,008 \pm 73$ & $9,393 \pm 1,002$ & $2,061 \pm 51$ & $10,661 \pm 729$
\end{tabular}

Table S2. Published results for alternative sample preparation platforms from greater than 1 cell and less than 1,000 cells.

\begin{tabular}{|c|c|c|c|c|}
\hline $\begin{array}{l}\text { Sample prep } \\
\text { method }\end{array}$ & Sample processed & Sample analyzed & $\begin{array}{l}\text { Number of protein } \\
\text { groups identified }\end{array}$ & Reference \\
\hline nanoPOTS & $\begin{array}{l}\text { 137-141 HeLa cells } \\
10-14 \text { HeLa cells }\end{array}$ & $\begin{array}{l}\text { whole } \\
\text { whole }\end{array}$ & $\begin{array}{r}3,056 \\
1,517\end{array}$ & 7 \\
\hline microPOTS & $\begin{array}{l}\text { 91-93 HeLa cells } \\
\text { 21-28 HeLa cells }\end{array}$ & $\begin{array}{l}\text { whole } \\
\text { whole }\end{array}$ & $\begin{array}{l}2,064 \\
1,252 \\
\end{array}$ & 8 \\
\hline iPAD-100 & 100 DLD cells & whole & 635 & 9 \\
\hline OAD & $\begin{array}{l}100 \text { HeLa cells } \\
10 \text { HeLa cells }\end{array}$ & $\begin{array}{l}\text { whole } \\
\text { whole }\end{array}$ & $\begin{array}{r}1,063 \\
108\end{array}$ & 10 \\
\hline ISPEC & $\begin{array}{l}1,000 \text { HeLa cells } \\
125 \pm 28 \text { HeLa cells } \\
12 \pm 2 \text { HeLa cells }\end{array}$ & $\begin{array}{l}\text { whole } \\
\text { whole } \\
\text { whole }\end{array}$ & $\begin{array}{r}2,079 \\
866 \\
64\end{array}$ & 11 \\
\hline DMF & $\begin{array}{l}500 \text { jurkat cells } \\
100 \text { jurkat cells }\end{array}$ & $\begin{array}{l}\text { whole } \\
\text { whole }\end{array}$ & $\begin{array}{l}\sim 2,500 \\
\sim 1,250\end{array}$ & 12 \\
\hline AFA & $\begin{array}{l}2,000 \text { MCF-7 cells } \\
2,000 \text { MCF-7 cells }\end{array}$ & $\begin{array}{l}122 \text { MCF-7 cells } \\
50 \text { MCF-7 cells }\end{array}$ & $\begin{array}{l}2,512 \\
1,802 \\
\end{array}$ & 13 \\
\hline autoSP3 & $\begin{array}{l}\text { 1,000 HeLa cells } \\
100 \text { HeLa cells }\end{array}$ & $\begin{array}{l}\text { whole } \\
\text { whole }\end{array}$ & $\begin{array}{r}\sim 1,000 \\
459\end{array}$ & 14 \\
\hline MICRO-FASP & $\begin{array}{l}1,000 \text { MCF-7 cells } \\
500 \text { MCF-7 cells } \\
100 \text { MCF-7 cells }\end{array}$ & $\begin{array}{l}\text { whole } \\
\text { whole } \\
\text { whole }\end{array}$ & $\begin{array}{r}r 3,050 \\
\sim 1,650 \\
\sim 500 \\
\end{array}$ & 15 \\
\hline FASP & 1,000 HeLa cells & whole & 1,100 & 16 \\
\hline
\end{tabular}


Table S3. Comparison of LC-MS/MS conditions between OmSET and MICRO-FASP sample preparation platforms.

\begin{tabular}{|c|c|c|c|c|c|c|c|c|}
\hline \multirow{2}{*}{$\begin{array}{c}\text { Sample } \\
\text { preparation } \\
\text { platform }\end{array}$} & \multicolumn{4}{|c|}{ LC column } & \multicolumn{3}{c|}{ LC conditions } \\
\cline { 2 - 9 } & $\begin{array}{c}\text { Column } \\
\text { type }\end{array}$ & $\begin{array}{c}\text { Particle } \\
\text { size }(\mu \mathrm{m})\end{array}$ & $\begin{array}{c}\text { Pore size } \\
(\AA)\end{array}$ & $\begin{array}{c}\text { i.d. } \\
(\mathrm{um})\end{array}$ & $\begin{array}{c}\text { Length } \\
(\mathrm{cm})\end{array}$ & $\begin{array}{c}\text { Flow rate } \\
(\mathrm{nL} / \mathrm{min})\end{array}$ & $\begin{array}{c}\text { Functional } \\
\text { gradient } \\
(\%)\end{array}$ & $\begin{array}{c}\text { Time } \\
(\mathrm{min})\end{array}$ \\
\hline $\begin{array}{c}\text { MICRO- } \\
\text { FASP }\end{array}$ & $\begin{array}{c}\text { Packed } \\
\text { C18 }\end{array}$ & 1.7 & 300 & 75 & 15 & 500 & $2-30$ & 210 \\
\hline OmSET & $\begin{array}{c}\text { Packed } \\
\text { C18 }\end{array}$ & 1.9 & 120 & 75 & 18 & 150 & $1-25$ & 60 \\
\hline
\end{tabular}

\begin{tabular}{|c|c|c|c|c|c|c|c|}
\hline \multicolumn{6}{|c|}{ MS information } & \multirow[b]{3}{*}{$\begin{array}{l}\text { Data } \\
\text { processing } \\
\text { software }\end{array}$} & \multirow[b]{3}{*}{ Reference } \\
\hline & & \multicolumn{2}{|c|}{ MS1 } & \multicolumn{2}{|r|}{ MS2 } & & \\
\hline Instrument & Resolution & $\begin{array}{l}\text { AGC } \\
\text { target }\end{array}$ & $\begin{array}{c}\text { Max ion } \\
\text { injection } \\
\text { time (ms) }\end{array}$ & $\begin{array}{l}\text { AGC } \\
\text { target }\end{array}$ & $\begin{array}{c}\text { Max ion } \\
\text { injection time } \\
(\mathrm{ms})\end{array}$ & & \\
\hline Q Exactive HF & 60,000 & 3.E+06 & 30 & 1.E+05 & 45 & $\begin{array}{l}\text { MaxQuant } \\
\text { (v1.6) }\end{array}$ & 15 \\
\hline $\begin{array}{c}\text { Orbitrap Fusion } \\
\text { Lumos }\end{array}$ & 120,000 & 4.E+05 & 50 & 3. E+04 & 35 & $\begin{array}{l}\text { Proteome } \\
\text { Discoverer } \\
\text { (v2.3) }\end{array}$ & - \\
\hline
\end{tabular}




\section{References}

1. MacLean, B.; Tomazela, D.M.; Shulman, N.; Chambers, M.; Finney, G.L.; Frewen, B.; Kern, R.; Tabb, D.L.; Liebler, D.C.; MacCoss, M.J. Skyline: an open source document editor for creating and analyzing targeted proteomics experiments. Bioinformatics. 2010, 26 (7), 966-968.

2. McDonald, W.H.; Tabb, D.L.; Sadygov, R.G.; MacCoss, M.J.; Venable, J.; Graumann, J.; Johnson, J.R.; Cociorva, D.; Yates, J.R., 3rd. MS1, MS2, and SQT-three unified, compact, and easily parsed file formats for the storage of shotgun proteomic spectra and identifications. Rapid Commun Mass Spectrom. 2004, 18 (18), 2162-2168.

3. Lam, H.; Deutsch, E.W.; Eddes, J.S.; Eng, J.K.; King, N.; Stein, S.E.; Aebersold, R. Development and validation of a spectral library searching method for peptide identification from MS/MS. Proteomics. 2007, 7 (5), 655-667.

4. Deutsch, E.W.; Mendoza, L.; Shteynberg, D.; Slagel, J.; Sun, Z.; Moritz, R.L. TransProteomic Pipeline, a standardized data processing pipeline for large-scale reproducible proteomics informatics. Proteomics Clin Appl. 2015, 9 (7-8), 745-754.

5. Klont, F.; Bras, L.; Wolters, J.C.; Ongay, S.; Bischoff, R.; Halmos, G.B.; Horvatovich, P. Assessment of Sample Preparation Bias in Mass Spectrometry-Based Proteomics. Anal Chem. 2018, 90 (8), 5405-5413.

6. Kyte, J. and Doolittle, R.F. A Simple Method for Displaying the Hydropathic Character of a Protein. J. Mol. Biol. 1982, 157, 105-132.

7. Zhu, Y.; Piehowski, P.D.; Zhao, R.; Chen, J.; Shen, Y.; Moore, R.J.; Shukla, A.K.; Petyuk, V.A.; Campbell-Thompson, M.; Mathews, C.E.; Smith, R.D.; Qian, W.J.; Kelly, R.T. Nanodroplet processing platform for deep and quantitative proteome profiling of $10-$ 100 mammalian cells. Nat Commun. 2018, 9 (1), No. 882.

8. Xu, K.; Liang, Y.; Piehowski, P.D.; Dou, M.; Schwarz, K.C.; Zhao, R.; Sontag, R.L.; Moore, R.J.; Zhu, Y.; Kelly, R.T. Benchtop-compatible sample processing workflow for proteome profiling of < 100 mammalian cells. Anal Bioanal Chem. 2019, 411 (19), 4587-4596.

9. Chen, Q.; Yan, G.; Gao, M.; Zhang, X. Ultrasensitive Proteome Profiling for 100 Living Cells by Direct Cell Injection, Online Digestion and Nano-LC-MS/MS Analysis. Anal Chem. 2015, 87 (13), 6674-6680.

10. Li, Z.Y.; Huang, M.; Wang, X.K.; Zhu, Y.; Li, J.S.; Wong, C.C.L.; Fang, Q. Nanoliter-Scale OilAir-Droplet Chip-Based Single Cell Proteomic Analysis. Anal Chem. 2018, 90 (8), 5430 5438.

11. Hata, K.; Izumi, Y.; Hara, T.; Matsumoto, M.; Bamba, T. In-Line Sample Processing System with an Immobilized Trypsin-Packed Fused-Silica Capillary Tube for the Proteomic Analysis of a Small Number of Mammalian Cells. Anal Chem. 2020, 92 (4), 2997-3005.

12. Leipert, J. and Tholey, A. Miniaturized sample preparation on a digital microfluidics device for sensitive bottom-up microproteomics of mammalian cells using magnetic beads and mass spectrometry-compatible surfactants. Lab Chip. 2019, 19 (20), 34903498.

13. Li, S.; Plouffe, B.D.; Belov, A.M.; Ray, S.; Wang, X.; Murthy, S.K.; Karger, B.L.; Ivanov, A.R. An Integrated Platform for Isolation, Processing, and Mass Spectrometry-based 
Proteomic Profiling of Rare Cells in Whole Blood. Mol Cell Proteomics. 2015, 14 (6), 1672-1683.

14. Muller, T.; Kalxdorf, M.; Longuespee, R.; Kazdal, D.N.; Stenzinger, A.; Krijgsveld, J. Automated sample preparation with SP3 for low-input clinical proteomics. Mol Syst Biol. 2020, 16 (1), No. e9111.

15. Zhang, Z.; Dubiak, K.M.; Huber, P.W.; Dovichi, N.J. Miniaturized Filter-Aided Sample Preparation (MICRO-FASP) Method for High Throughput, Ultrasensitive Proteomics Sample Preparation Reveals Proteome Asymmetry in Xenopus laevis Embryos. Anal Chem. 2020, 92 (7), 5554-5560.

16. Wisniewski, J.R.; Ostasiewicz, P.; Mann, M. High recovery FASP applied to the proteomic analysis of microdissected formalin fixed paraffin embedded cancer tissues retrieves known colon cancer markers. J Proteome Res. 2011, 10 (7), 3040-3049. 